\title{
The Effect of Subclinical Ketosis in Early Lactation on Reproductive Performance of Postpartum Dairy Cows
}

\author{
R. B. Walsh, ${ }^{\star 1}$ J. S. Walton,† D. F. Kelton, ${ }^{\star}$ S. J. LeBlanc, ${ }^{\star}$ K. E. Leslie, ${ }^{*}$ and T. F. Duffield ${ }^{\star}$ \\ *Department of Population Medicine, and \\ †Department of Animal and Poultry Science, University of Guelph, Ontario, Canada, N1G 2W1
}

\begin{abstract}
Data generated from 796 Holstein cows enrolled in a clinical trial to investigate the health effect of a monensin controlled release capsule were analyzed to investigate the association between circulating serum $\beta$-hydroxybutyrate (BHBA) concentration in the periparturient period and subsequent reproductive performance. Overall, accounting for both repeated measures within cow and clustering at the herd level, non-pregnant cows after first insemination tended to have increased circulating BHBA concentrations from $3 \mathrm{wk}$ before calving to $9 \mathrm{wk}$ after calving relative to pregnant cows. Including the interaction between the week of sample collection and pregnancy outcome, non-pregnant cows had higher circulating BHBA concentrations in the second week after calving than cows diagnosed pregnant after first artificial insemination. Within individual weeks, cows with circulating BHBA concentrations $\geq 1,000 \mu \mathrm{mol} / \mathrm{L}$ in the first week postpartum were less likely to be diagnosed pregnant after first insemination. In the second week postpartum, the cows with circulating BHBA concentrations $\geq 1,400 \mu \mathrm{mol} / \mathrm{L}$ were significantly less likely to be pregnant after first artificial insemination. A dose response relationship was found when a comparison of the probability of pregnancy after first insemination and duration of elevated circulating ketone bodies was investigated. The probability of pregnancy was reduced by $20 \%$ in cows diagnosed subclinically ketotic in either the first or second week postpartum. Nevertheless, cows above the subclinical ketosis threshold in both the first and second week postpartum were $50 \%$ less likely to be pregnant after first insemination. Similarly, the median time to pregnancy increased in cows experiencing elevated BHBA concentrations in either $(124 \mathrm{~d})$ or both $(130 \mathrm{~d})$ the first and second week postpartum relative to cows never experiencing elevated BHBA concentrations (108
\end{abstract}

Received August 28, 2006.

Accepted January 31, 2007.

${ }^{1}$ Corresponding author: rwalsh@uoguelph.ca d). To further investigate this, the effect of elevated circulating BHBA was permitted to vary with time. The effect decreased with time, such that the daily probability of pregnancy increased similar to nonsubclinically ketotic cows by approximately $160 \mathrm{~d}$ in milk. From this analysis, both the relative circulating concentration of BHBA and the duration of elevated circulating BHBA were negatively associated with the probability of pregnancy at first service.

Key words: subclinical ketosis, $\beta$-hydroxybutyrate, time to pregnancy

\section{INTRODUCTION}

The concept of homeorhesis or prioritization of energy distribution to meet specific physiological demands was refined in 1980 (Bauman and Currie, 1980). Partitioning of available energy to milk production early in lactation, at the expense of reproduction, has formed a conceptual framework to address the effect of negative energy balance on future reproductive performance, as measured by the time to establishment of luteal activity, probability of pregnancy after first AI [pregnancy risk (PR)/AI], and time to conception.

Cows experiencing delayed onset of luteal activity postpartum typically have lower DMI, produce less milk, and subsequently lose more body condition early in lactation (Staples et al., 1990). At the whole-animal level, the magnitude and duration of negative energy balance are influenced by feed intake and milk production. At the organ and molecular level, variation in energy utilization efficiency, ranging from rumen function to the ability of the liver to repartition mobilized fat, affect energy balance status.

Previous research has reported an association between calculated negative energy balance and reproductive traits, including days to first luteal activity, first service conception risk, days from calving to AI, and days from calving to conception (Villa-Godoy et al., 1988; Staples et al., 1990; Reist et al., 2003b). The physiological state of energy deficiency impairs hypothalamic responsiveness to circulating estradiol-17 $\beta$, resulting in reduced GnRH pulse frequency and con- 
comitant reduction in LH required for follicular deviation and eventual ovulation (Jolly et al., 1995; Dawuda et al., 2002; Butler, 2003).

Energy balance is dependent on many factors. Various metabolic and endocrine blood and milk measures such as NEFA, ketone bodies, glucose, insulin, milk fat, or fat:protein ratio are indirect measures of energy balance. Circulating ketones increase when the maximal ability of the liver to oxidize NEFA and store triacylglycerol is exceeded. Associations between elevated circulating ketone concentration and periparturient uterine disease were described by Reist et al. (2003a); however, investigation of thresholds was based on the distribution of circulating ketone concentrations or anecdotal experience rather than the associated change in the risk of disease (Duffield et al., 1998). Similarly, the effect of postpartum circulating ketone concentration on PR/AI, time to commencement of luteal activity, and time to pregnancy has been described later in lactation with variable results (Andersson and Emanuelson, 1984; Cook et al., 2001). A circulating BHBA concentration threshold immediately postpartum, defined by demonstrable reduction in the PR/AI, has not been validated.

The objectives of this retrospective analysis were to investigate relationships between the magnitude and duration of increased serum BHBA measured at $-3 \mathrm{wk}$ and in each of the first, second, third, sixth, and ninth weeks postpartum and the PR/AI, the time from calving to first AI, and time from calving to pregnancy.

\section{MATERIALS AND METHODS}

Data were collected as part of a clinical trial to determine the effect of prepartum administration of monensin as a controlled release capsule (CRC) on postpartum health, energy balance, and reproductive performance (Duffield et al., 1998, 1999). Briefly, 25 Holstein herds around Guelph, Ontario, Canada, that were enrolled in milk recording through Ontario DHI were studied from March 1995 to December 1995. Herd size ranged from 25 to 160 lactating animals, with 305-d rolling herd average for milk production from 7,000 to $10,000 \mathrm{~kg}$. Five herds were fed a TMR, and the remaining herds had a component feeding system. A technician visited each farm weekly at a consistent time of day. At each weekly visit, the technician administered the randomly assigned treatment (monensin CRC or placebo); recorded animal data including lactation, season of calving (winter: December through February; spring: March through May; summer: June through August; fall: September through November), and BCS (Ferguson et al., 1994; $\leq 2.5$ thin; $\geq 2.75$ to $\leq 3.5$ fair; $\geq 3.75$ fat); and collected blood samples. Each blood sample was collected from a coccygeal blood vessel into a $10-\mathrm{mL}$ vacuum tube (Monoject red stopper blood collection tubes; Sherwood Medical, St. Louis, MO). Blood was collected at the time of monensin CRC or placebo oral administration $3 \mathrm{wk}$ before calving and at wk 1, 2, 3, 6 , and 9 postpartum. Blood samples were stored, on ice, in an insulated cooler from time of collection until sample processing occurred. Within $5 \mathrm{~h}$ postcollection, blood samples were centrifuged at $733 \times g$ for $10 \mathrm{~min}$. The samples of serum were submitted to the Clinical Pathology Laboratory (Department of Pathobiology, Ontario Veterinary College) for the measurement of $\mathrm{Ca}$, $P$, total protein, urea, glucose, and BHBA concentrations and determination of aspartate aminotransferase activity using an automated analyzer (Dacos 2 analyzer; Coulter Electronics, Hialeah, FL).

Peripartum disease information including dystocia (veterinary-assisted parturition), retained placenta (failure to pass the fetal membranes within $24 \mathrm{~h}$ ), milk fever (veterinary diagnosed), metritis (inflammation of the uterus $<15$ DIM), clinical ketosis, displaced abomasum (left or right displacement diagnosed by a veterinarian), respiratory illness, and lameness was captured in on-farm data sheets, veterinary records, and on-farm computer record systems (Duffield et al., 1999). Reproductive data, including DIM at first insemination, conception date, number of inseminations, herd removal date, and pregnancy status at removal, were recorded using the same methods. There was minimal use of ovulation synchronization protocols. Pregnancy diagnosis was performed at least $40 \mathrm{~d}$ after insemination by rectal palpation. Five herds had first lactation animals excluded, because they had been exposed to a monensin premix within $4 \mathrm{wk}$ of parturition.

\section{Data Management and Statistical Analysis}

Statistical analysis was performed using Intercooled Stata 9.1 (StataCorp LP, College Station, TX) and SAS (SAS Inst. Inc., Cary, NC). Descriptive statistics were used to characterize animals diagnosed pregnant after first insemination, relative to animals diagnosed not pregnant. Data were collected as part of a clinical trial; therefore, treatment remained in all analyses.

The shape of the BHBA curve between weeks was assessed using PROC MIXED in SAS (SAS Institute, 2004), accounting for the random effect of herd and repeated measures of cows within herd. After transforming the BHBA data into the natural logarithm scale, variables offered to the model included treatment, parity, periparturient disease, the pregnancy status diagnosed after first AI, and all 2-way interactions. Residual analysis was performed at the cow level. The distribution of residuals was symmetrical with long 
tails, thus violating the normality of residual assumption. To investigate the effect of influential observations (extreme values in the independent or dependent variables), they were removed from the analysis. Removal of influential observations improved the normality of residual assumption without affecting the direction of the reported coefficients indicating that the observed effect was not solely due to the effect of extreme observations. Final models included all observations. Least squares means of weekly BHBA concentration were estimated for pregnant and non-pregnant cows at each weekly measurement. To appropriately account for the repeated measures within cow, a postestimation adjustment was performed on the reported probability value using the Bonferroni-Sidak adjustment to account for correlation between sampling intervals.

The effect of BHBA concentration at each week on probability of pregnancy at first insemination was assessed using multivariable logistic regression accounting for correlation of cows within herd using a generalized estimating equation with an exchangeable correlation structure. Cow level variables offered to the model included parity, season of calving, initial BCS, BCS at 60 DIM, change in BCS, season of calving, and peripartum disease information. Herd level variables included farm type (free stall vs. tie stall) and herd size. Treatment with monensin was retained in all models, because the data were generated as part of a monensin clinical trial. Initial screening of variables was performed using a manual backward stepwise procedure with significant variables $(P<0.1)$ remaining in the model. This procedure was repeated for each week postpartum in which serum BHBA measurements were available. Initially, serum BHBA was offered as a continuous variable. Subsequently, based on the appearance of a smoothed scatterplot of serum BHBA and probability of pregnancy at first AI, realistic thresholds were created at $200 \mu \mathrm{mol} / \mathrm{L}$ increments from 1,000 to $1,600 \mu \mathrm{mol} / \mathrm{L}$. Ultimately, sequential multivariable logistic regression, accounting for the effect of clustering at the herd level, was applied based on the predicted thresholds to evaluate their potential significance.

The effect of prolonged exposure to elevated ketone bodies on PR at first insemination was investigated by generating a composite variable representing the additive effect of the number of weeks with serum BHBA $\geq 1,000 \mu \mathrm{mol} / \mathrm{L}$ in the first week and $\geq 1,400 \mu \mathrm{mol} /$ $\mathrm{L}$ in the second week.

Finally, time from calving to first insemination and time to pregnancy were modeled using semiparametric survival analysis. This method accounted for animals that did not become pregnant. Robust standard errors were generated to account for clustering of animals within herds. Plotting the cumulative hazard relative
Table 1. Characterization of 796 Holstein dairy cattle from 25 Ontario herds diagnosed pregnant or non-pregnant after first insemination

\begin{tabular}{lcc}
\hline Items & \multicolumn{1}{c}{ Pregnant } & Non-pregnant \\
\hline Number of cows & 277 & 519 \\
Parity $^{1}$ & $2.6(2.3$ to 2.7$)$ & $2.6(2.5$ to 2.8$)$ \\
Days to first insemination $^{1}$ & $80.4(77.3$ to 83.5$)$ & $79.4(77.1$ to 81.8$)$ \\
BCS $^{1}$ & $3.44(3.35$ to 3.43$)$ & $3.39(3.43$ to 3.5$)$ \\
CRC $^{2}$ & $50.9(141)$ & $49.9(257)$ \\
Periparturient disease $^{3}$ & & \\
Retained placenta & $6.9(19)$ & $7.7(40)$ \\
Metritis & $2.5(78)$ & $3.1(16)$ \\
Milk fever & $6.5(18)$ & $6.7(35)$ \\
Displaced abomasum & $2.9(8)$ & $4.2(22)$ \\
Mastitis & $13.4(37)$ & $15.2(79)$ \\
Lame & $2.2(6)$ & $1.9(10)$ \\
Dystocia & $2.5(7)$ & $1.7(9)$ \\
Cystic ovarian disease & $3.2(9)$ & $1.7(9)$ \\
Endometritis & $2.9(8)$ & $3.1(16)$ \\
\hline
\end{tabular}

${ }^{1}$ Mean (95\% confidence interval).

${ }^{2}$ Proportion of randomly assigned treatments with the monensin controlled release capsule (CRC).

${ }^{3}$ Proportion (n).

to modified Cox-Snell residuals assessed goodness of fit. Animals with survival times less than 30 DIM were excluded from this analysis, because they were not at risk for pregnancy, and they did not complete the sampling protocol. The proportionality assumption was assessed graphically by plotting the logarithm of the hazard function against the logarithm of time. The Akaike information criterion was used to assess the overall fit of the final model. Delta-beta-like residuals were used to identify points of leverage, whereas deviance residuals were calculated and sorted to identify possible outliers.

\section{RESULTS}

The prevalence of dystocia, twins, peripartum disease, reproductive abnormalities, and other health events in the present data were reported previously (Duffield et al., 1999). Briefly, treatment with a monensin CRC reduced the risk of displacement of the abomasum by $40 \%$ [odds ratio $(\mathbf{O R})=0.59 ; P=0.004$ ] and the risk of multiple illnesses by $40 \%(\mathrm{OR}=0.6 ; P=0.01)$.

The data and outcome of first insemination were recorded for 796 cows. The PR/AI at first insemination was $34.8 \%$. Further characterizations of animals based on pregnancy result to first AI are presented in Table 1. Median time from calving to first insemination was $74 \mathrm{~d}$, ranging from 31 to $243 \mathrm{~d}$. Days in milk at first AI, parity, season of calving, and periparturient disease were significant in a model to determine risk factors for PR/AI. A BCS of 3.25 to 3.75 was assigned to $86 \%$ of animals independent of treatment. Treatment did not affect the probability of pregnancy at first AI (mo- 


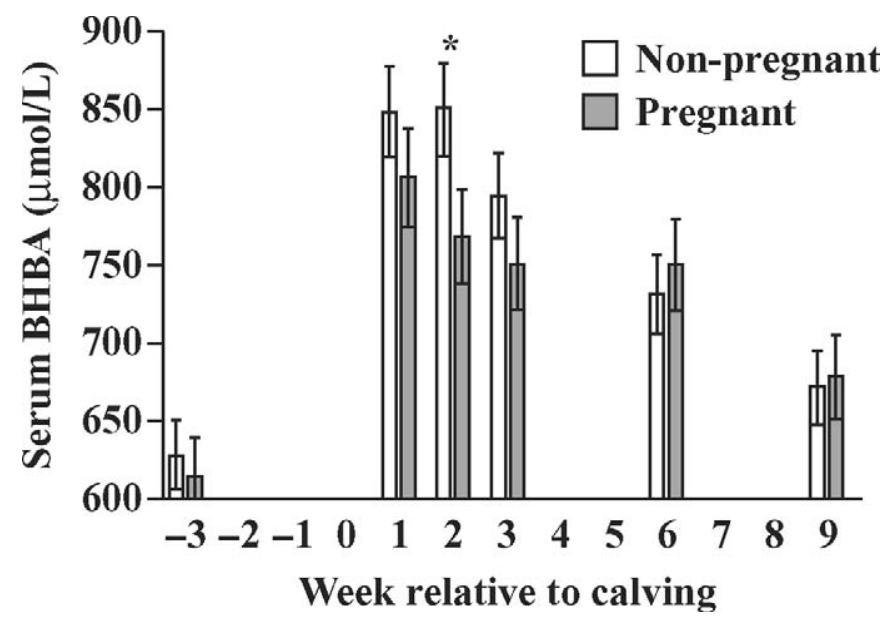

Figure 1. Least squares mean serum BHBA concentrations and standard error accounting for the random effect of herd and repeated measures with unequal spacing and adjusting for treatment and parity in Holstein cows that were subsequently diagnosed pregnant or non-pregnant after first insemination. Each cow was sampled once in the third week before calving, in each of the first $3 \mathrm{wk}$, and again in the sixth and ninth weeks after calving. ${ }^{*} P<0.05$.

nensin-treated group, $35.2 \%$; placebo group $34.5 \%$; $\mathrm{OR}=1.03 ; P=0.84)$.

Cows diagnosed non-pregnant after first $\mathrm{AI}$ tended to have increased circulating BHBA concentrations from 3 wk before calving to 9 wk after calving relative to cows diagnosed pregnant after first $\mathrm{AI}(P=0.09)$ accounting for monensin treatment and parity. A tendency for an interaction between the week of sample and pregnancy status after first AI was identified $(P=0.1)$. This interaction term was significant at wk 2 . Least squares means were calculated at each sampling period for pregnant and non-pregnant cows and compared adjusting for repeated measures within cow. Nonpregnant cows had increased circulating BHBA concentrations relative to pregnant cows in the second week after calving $(P=0.03$; Figure 1). Treatment with the monensin CRC reduced the BHBA estimate at each sampling point ( $P$ $<0.001$ ). Periparturient disease did not significantly alter the shape of the BHBA curve. Neither initial BCS, final BCS (thin, fair, fat), nor BCS change ( $\geq 1$ unit) was significant in a model of factors affecting the probability of pregnancy at first AI.

Within individual weeks after calving, an association between serum BHBA concentration and the PR/AI was identified, accounting for the effect of correlation of cows within a herd. The PR/AI was reduced by $2 \%(\mathrm{OR}=$ $0.98, P=0.06)$ in wk 1 and $3 \%(\mathrm{OR}=0.97, P=0.01)$ in wk 2 for each $100 \mu \mathrm{mol}$ of BHBA/L increase. Although the reported OR appears exceedingly small, the range of serum BHBA reported is wide in both wk 1 and wk 2 (mean \pm SE; range: $1,032.4 \pm 27.6,101$ to 9,382 vs.

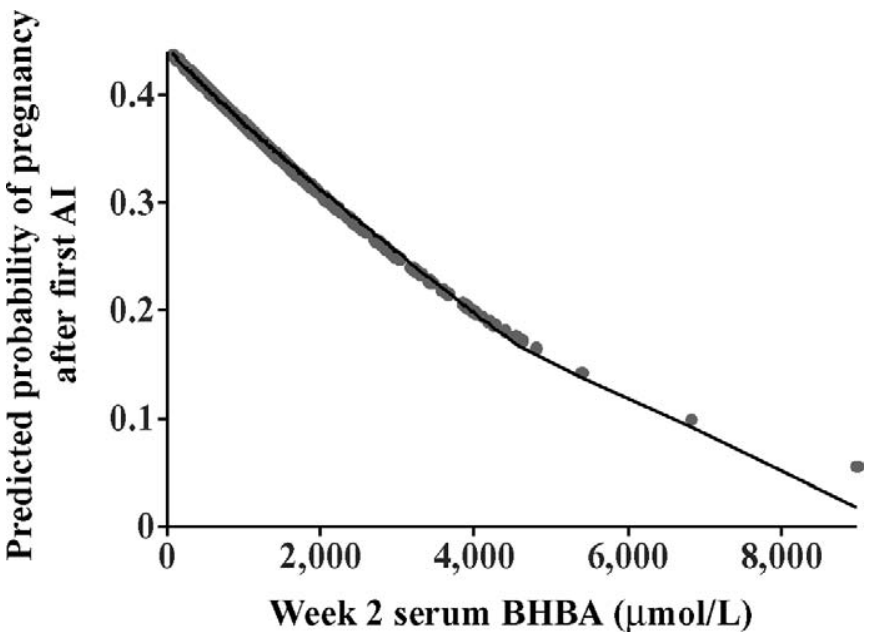

Figure 2. Predicted probability of pregnancy generated through multivariable logisitic regression accounting for the correlation of cows within herds relative to serum BHBA concentration determined in the second week postpartum in 796 Holstein dairy cows.

$1,064.0 \pm 30.1,66$ to 8,976 , respectively). The predicted probability of pregnancy, relative to circulating BHBA concentration for the second week postpartum is presented in Figure 2. Serum BHBA in wk 3, 6, and 9 were not significantly associated with PR.

The proportion of animals classified as subclinically ketotic (SCK) at the predetermined thresholds by first service conception is presented in Table 2 . From these models, cows with serum BHBA $\geq 1,000 \mu \mathrm{mol} / \mathrm{L}$ in wk 1 or $\geq 1,400 \mu \mathrm{mol} / \mathrm{L}$ in wk 2 were significantly less likely to be diagnosed pregnant after first insemination. There were a total of 288 animals with serum $\mathrm{BHBA} \geq 1,000$ $\mu \mathrm{mol} / \mathrm{L}$ in wk 1 , and 150 cows were $\geq 1,400 \mu \mathrm{mol} / \mathrm{L}$ in wk 2. A total of 104 cows were classified as SCK in both wk 1 and 2.

Given the available data, evaluation of the effect of prolonged exposure to elevated ketones was limited to analysis of the number of weeks above a series of thresholds. A dose response curve was identified when modeling the number of weeks positive without specifying the order of weeks positive and using a 1,000 $\mu \mathrm{mol} / \mathrm{L}$ threshold in wk 1 and the $1,400 \mu \mathrm{mol} / \mathrm{L}$ threshold in wk 2 (Table 3).

Survival analysis was used to measure the time from calving to first insemination and from calving to pregnancy. The daily probability of AI was reduced in cows classified as SCK in either wk 1 or 2 relative to cows never classified as SCK $(P=0.04$; Table 4$)$. Further, median time to first AI was delayed $(P<0.01)$ for cows calving in the spring relative to cows calving in the fall [median, 95\% confidence interval $(\mathbf{C I})$ spring $=81 \mathrm{~d}$ $(95 \% \mathrm{CI}=78$ to $85 \mathrm{~d}$; fall $70 \mathrm{~d}, 68$ to $72 \mathrm{~d})$ ]. 
Table 2. Investigation of the effect of serum BHBA threshold on the probability of pregnancy after first insemination in 796 lactating Holstein dairy cows from 25 Ontario herds

\begin{tabular}{ccccccccc}
\hline Week & $\begin{array}{c}\text { Threshold } \\
\text { ( } \mu \text { mol of } \\
\text { BHBA/L) }\end{array}$ & $\mathrm{n}$ & $\begin{array}{c}\text { Pregnant } \\
\text { below } \\
\text { threshold }(\%)\end{array}$ & $\mathrm{n}$ & $\begin{array}{c}\text { Pregnant } \\
\text { at or above } \\
\text { threshold }(\%)\end{array}$ & OR $^{1}$ & $P$ & $\begin{array}{c}\text { 95\% } \\
\text { confidence } \\
\text { interval }\end{array}$ \\
\hline 1 & $\geq 1,000$ & 508 & 37.9 & 288 & 29.2 & 0.73 & 0.04 & 0.54 to 0.99 \\
& $\geq 1,200$ & 606 & 36.6 & 190 & 28.9 & 0.78 & 0.16 & 0.55 to 1.10 \\
& $\geq 1,400$ & 670 & 36.1 & 126 & 27.7 & 0.75 & 0.21 & 0.52 to 1.15 \\
2 & $\geq 1,600$ & 705 & 35.8 & 91 & 26.3 & 0.75 & 0.22 & 0.47 to 1.19 \\
& $\geq 1,000$ & 532 & 37.5 & 270 & 31.0 & 0.89 & 0.47 & 0.65 to 1.22 \\
& $\geq 1,200$ & 601 & 37.0 & 201 & 28.9 & 0.87 & 0.42 & 0.62 to 1.22 \\
& $\geq 1,400$ & 651 & 37.9 & 151 & 22.5 & 0.60 & 0.01 & 0.40 to 0.88 \\
& $\geq 1,600$ & 685 & 37.8 & 117 & 18.8 & 0.48 & 0.002 & 0.31 to 0.76 \\
& $\geq 1,000$ & 570 & 36.6 & 231 & 31.1 & 0.96 & 0.83 & 0.70 to 1.33 \\
& $\geq 1,200$ & 636 & 36.9 & 165 & 27.8 & 0.82 & 0.30 & 0.57 to 1.19 \\
& $\geq 1,400$ & 674 & 36.4 & 127 & 28.8 & 0.88 & 0.54 & 0.59 to 1.32 \\
& $\geq 1,600$ & 697 & 36.5 & 104 & 25.0 & 0.75 & 0.20 & 0.48 to 1.17 \\
& $\geq 1,000$ & 602 & 35.2 & 194 & 37.9 & 1.01 & 0.97 & 0.72 to 1.40 \\
& $\geq 1,200$ & 674 & 34.8 & 122 & 35.2 & 1.10 & 0.69 & 0.74 to 1.40 \\
& $\geq 1,400$ & 724 & 35.6 & 72 & 27.7 & 0.72 & 0.21 & 0.44 to 1.20 \\
& $\geq 1,600$ & 746 & 35.1 & 50 & 32.0 & 0.90 & 0.73 & 0.50 to 1.61 \\
& $\geq 1,000$ & 664 & 35.7 & 129 & 31.8 & 0.87 & 0.47 & 0.59 to 1.28 \\
& $\geq 1,200$ & 742 & 35.4 & 51 & 29.0 & 0.72 & 0.28 & 0.40 to 1.31 \\
& $\geq 1,400$ & 768 & 35.4 & 25 & 24.0 & 0.57 & 0.21 & 0.24 to 1.38 \\
& $\geq 1,600$ & 776 & 35.2 & 17 & 29.4 & 0.80 & 0.67 & 0.30 to 2.18 \\
& &
\end{tabular}

${ }^{1}$ Odds ratio (OR) determined by logistic regression controlling for the effect of treatment with monensin controlled release capsule and clustering at the herd level. Each week modeled individually.

Median time to pregnancy for animals never classified as SCK was $108 \mathrm{~d}(95 \% \mathrm{CI}=102$ to 112$)$ relative to $124 \mathrm{~d}(95 \% \mathrm{CI}=116$ to $132 \mathrm{~d}$ ) for animals above the threshold in either wk 1 or 2 and $130 \mathrm{~d}(95 \% \mathrm{CI}=115$ to $136 \mathrm{~d}$ ) for animals greater than the BHBA threshold in both wk 1 and 2 . The proportional hazard assumption was violated in this data set. Therefore, the effect of exceeding the BHBA threshold was permitted to vary over time. This correction significantly improved the fit to the model. Controlling for season of calving and monensin treatment, the daily probability of pregnancy was reduced in cows classified as SCK in either or both wk 1 or 2 relative to cows never classified as SCK (Table 5). The effect of elevated BHBA concentration remained until approximately 140 DIM, after which the daily

Table 3. Effect of prolonged elevation of serum BHBA concentration on the probability of pregnancy after first insemination in 796 lactating Holstein dairy cattle from 25 Ontario herds

\begin{tabular}{lccc}
\hline Item & $\mathrm{OR}^{1}$ & $P$ & $\begin{array}{c}95 \% \text { confidence } \\
\text { interval }\end{array}$ \\
\hline > Threshold either week $^{2}$ & 0.83 & 0.281 & 0.60 to 1.15 \\
> Threshold both weeks $^{3}$ & $\begin{array}{c}0.47 \\
\text { Referent }\end{array}$ & 0.003 & 0.29 to 0.77 \\
Never subclinically ketotic & & \\
\hline
\end{tabular}

\footnotetext{
${ }^{1}$ Odds ratio (OR) adjusting for the effect of clustering at the herd level.

${ }^{2} \geq 1,000 \mu \mathrm{mol}$ of $\mathrm{BHBA} / \mathrm{L}$ in wk 1 or $\geq 1,400 \mu \mathrm{mol}$ of $\mathrm{BHBA} / \mathrm{L}$ in wk 2.

${ }^{3} \geq 1,000 \mu \mathrm{mol}$ of $\mathrm{BHBA} / \mathrm{L}$ in wk 1 and $\geq 1,400 \mu \mathrm{mol}$ of $\mathrm{BHBA} / \mathrm{L}$ in wk 2 .
}

probability of pregnancy, measured using the adjusted hazard ratio (HR), between SCK and non-SCK cows was equivalent (Table 6; Figure 3).

\section{DISCUSSION}

Postpartum hyperketonemia has repeatedly been associated with reduced reproductive performance in lactating cows. The current analysis offers several unique opportunities. First, the large number of individual cows that were followed continuously from before calving, weekly for the first $3 \mathrm{wk}$ after calving, and again in the sixth and ninth weeks allows investigation of the differences in energy status between cows over the transition period and within individual weeks. A comprehensive investigation of the effect of magnitude and duration of hyperketonemia on reproductive performance would best be calculated using the cumulative exposure to elevated circulating BHBA concentrations. Unfortunately, the sampling frequency combined with a lack of information on the typical duration of ketosis prevented this calculation in this data. Second, this data set predates ovulation synchronization protocols and as such offers a unique opportunity to investigate the association between SCK and time to insemination and other reproductive performance traits. Third, the large number of herds enrolled permits description of the average effect of SCK in lactating dairy cows on reproductive performance controlling for differences in management conditions. 
Table 4. Final Cox proportional hazard model of the effect of the number of weeks cows were classified as subclinically ketotic (SCK) based on circulating serum BHBA concentration on days from calving to first insemination in 796 Holstein dairy cows from 25 herds in Ontario, Canada

\begin{tabular}{|c|c|c|c|}
\hline Variable & $\mathrm{HR}^{1}$ & $P$ & $\begin{array}{l}95 \% \text { confidence } \\
\text { interval }\end{array}$ \\
\hline \multicolumn{4}{|c|}{ Numbers of weeks above SCK threshold } \\
\hline Either week ${ }^{2}$ & 0.85 & 0.04 & 0.74 to 0.99 \\
\hline Both weeks ${ }^{3}$ & 0.93 & 0.48 & 0.76 to 1.13 \\
\hline Never & Referent & & \\
\hline \multicolumn{4}{|l|}{ Treatment } \\
\hline Monensin ${ }^{4}$ & 0.87 & 0.05 & 0.76 to 1.00 \\
\hline Placebo & Referent & & \\
\hline \multicolumn{4}{|c|}{ Season of calving } \\
\hline Spring & 0.67 & $<0.001$ & 0.54 to 0.83 \\
\hline Summer & 0.88 & 0.13 & 0.76 to 1.03 \\
\hline Winter & 0.87 & 0.32 & 0.68 to 1.13 \\
\hline Fall & Referent & & \\
\hline
\end{tabular}

${ }^{1} \mathrm{HR}=$ hazard ratio

${ }^{2} \geq 1,000 \mu \mathrm{mol}$ of BHBA/L in wk 1 or $\geq 1,400 \mu \mathrm{mol}$ of BHBA/L in wk 2 .

${ }^{3} \geq 1,000 \mu \mathrm{mol}$ of BHBA/L in wk 1 and $\geq 1,400 \mu \mathrm{mol}$ of BHBA/L in wk 2 .

${ }^{4}$ Relative to cows randomly assigned to receive the placebo device.

There was a tendency for increased circulating BHBA concentrations in non-pregnant cows after first AI from $3 \mathrm{wk}$ before calving to $9 \mathrm{wk}$ after calving relative to cows diagnosed pregnant. The delayed effect of negative energy balance or hyperketonemia on reproductive performance is well documented. Both the duration and magnitude of negative energy balance are associated with reduced hypothalamic GnRH pulse frequency and perpetuation of an inappropriate negative feedback loop between estradiol concentration and the required LH release necessary to support follicular deviation and ovulation. This failure of communication along the hypothalamic-pituitary-ovarian axis is the most common physiologic lesion associated with negative energy balance and leads to delayed resumption of luteal activity (Reist et al., 2000; Butler, 2003).

Within individual weeks, the probability of pregnancy after first AI decreased linearly with increasing circulating BHBA concentration in both wk 1 and 2 . A $3 \%$ reduction in probability of pregnancy for each 100 $\mu \mathrm{mol}$ of BHBA/L increase was significant in wk 2 (Figure 2). This difference is relatively small; however, the range of values observed in the second week makes this finding very large at BHBA concentrations $>1,400$ $\mu \mathrm{mol} / \mathrm{L}$. Pregnancy risk at first insemination was not significantly affected by BHBA concentrations in wk

Table 5. Final Cox proportional hazard model of the effect of number of weeks cows were classified as subclinically ketotic (SCK) based on circulating serum BHBA concentrations on days from calving to conception in 796 Holstein dairy cows from 25 herds in Ontario, Canada

\begin{tabular}{|c|c|c|c|c|c|c|}
\hline Variable & $\mathrm{HR}^{1}$ & $P$ & $\begin{array}{c}95 \% \text { confidence } \\
\text { interval }\end{array}$ & $\mathrm{TVC}^{2}$ & $P$ & $\begin{array}{c}95 \% \text { confidence } \\
\text { interval }\end{array}$ \\
\hline \multicolumn{7}{|c|}{ Number of weeks above SCK threshold } \\
\hline Either week ${ }^{3}$ & 0.089 & $<0.001$ & 0.02 to 0.33 & 1.56 & 0.001 & 1.21 to 2.11 \\
\hline Both weeks ${ }^{4}$ & 0.029 & $<0.001$ & 0.004 to 0.21 & 2.02 & 0.001 & 1.32 to 3.12 \\
\hline Never & Referent & & & & & \\
\hline \multicolumn{7}{|l|}{ Treatment } \\
\hline Monensin 5 & 0.84 & 0.04 & 0.72 to 0.99 & & & \\
\hline Placebo & Referent & & & & & \\
\hline \multicolumn{7}{|c|}{ Season of calving } \\
\hline Spring & 0.65 & $<0.001$ & 0.52 to 0.81 & & & \\
\hline Summer & 0.88 & 0.22 & 0.72 to 1.08 & & & \\
\hline Winter & 1.07 & 0.64 & 0.81 to 1.41 & & & \\
\hline Fall & Referent & & & & & \\
\hline
\end{tabular}

${ }^{1} \mathrm{HR}=$ hazard ratio.

${ }^{2} \mathrm{TVC}=$ time varying covariate estimate varying with the natural logarithm of time.

${ }^{3} \geq 1,000 \mu \mathrm{mol}$ of BHBA/L in wk 1 or $\geq 1,400 \mu \mathrm{mol}$ of BHBA/L in wk 2 .

${ }^{4} \geq 1,000 \mu \mathrm{mol}$ of BHBA/L in wk 1 and $\geq 1,400 \mu \mathrm{mol}$ of BHBA/L in wk 2 .

${ }^{5}$ Relative to cows randomly assigned to receive the placebo device. 
Table 6. Adjusted hazard ratio (AHR) representing the relative effect of classification as subclinically ketotic (SCK; serum BHBA concentration $\geq 1,000 \mu \mathrm{mol} / \mathrm{L}$ in wk 1 or $\geq 1,400 \mu \mathrm{mol} / \mathrm{L}$ in wk 2 ) in either or both of the first 2 wk postpartum on the daily probability of pregnancy at selected time intervals after calving

\begin{tabular}{|c|c|c|}
\hline \multirow[b]{2}{*}{$\begin{array}{l}\text { Time } \\
\text { (DIM) }\end{array}$} & \multicolumn{2}{|c|}{$\mathrm{AHR}^{1}$} \\
\hline & $\begin{array}{c}>\text { SCK threshold } \\
\text { either week }\end{array}$ & $\begin{array}{c}>\text { SCK threshold } \\
\text { both weeks }\end{array}$ \\
\hline 80 & 0.62 & 0.63 \\
\hline 100 & 0.68 & 0.74 \\
\hline 120 & 0.75 & 0.84 \\
\hline 140 & 0.80 & 0.93 \\
\hline 160 & 0.85 & 1.02 \\
\hline
\end{tabular}

${ }^{1}$ Hazard ratio $\times$ time varying covariate $\mathrm{e}^{\ln (\text { time })}$.

$-3,3,6$, or 9 . A strong association between elevated circulating ketone concentration in the first week postpartum and risk of uterine disease was reported (Reist et al., 2003a). Significant associations between proportion of lactating cows cycling by $30 \mathrm{DIM}, \mathrm{PR} / \mathrm{AI}$, and proportion pregnant by $80 \mathrm{DIM}$ have been reported with hyperketonemia from the second to fifth week after calving (Plym Forshell et al., 1991; Reist et al., 2000; Koller et al., 2003).

Within individual weeks and using thresholds, cows with circulating BHBA concentrations $\geq 1,000 \mu \mathrm{mol} / \mathrm{L}$ ( $40 \%$ of cows) in the first week and $\geq 1,400 \mu \mathrm{mol} / \mathrm{L}$ (19\% of cows) in the second week were at significantly increased risk of non-pregnancy after first insemination (Table 2). In the first week after calving, a $25 \%$ reduction in the probability of pregnancy was consistently

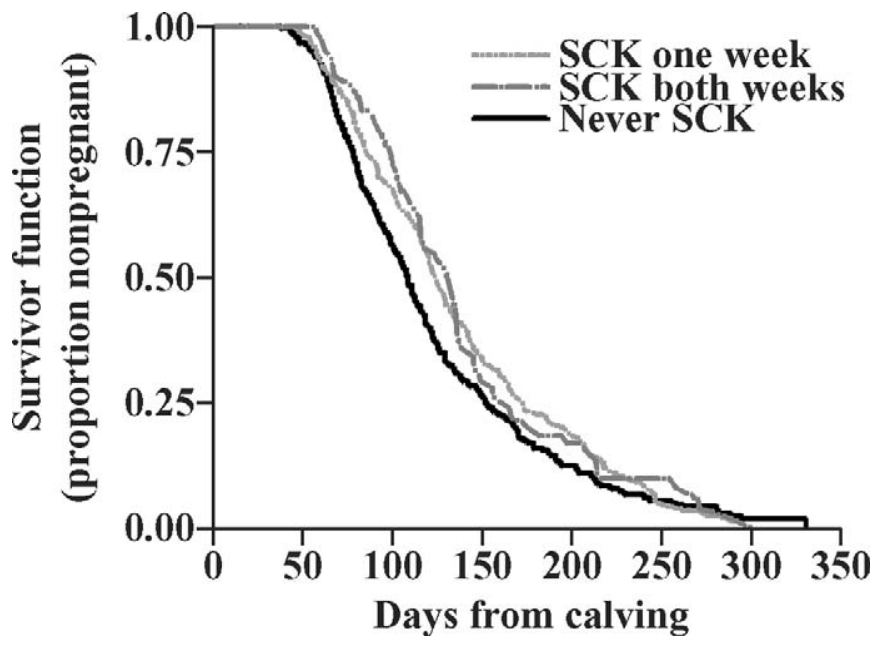

Figure 3. Survival curves of time to pregnancy for 796 lactating Holstein cows classified as subclinically ketotic (SCK) based on serum BHBA concentration determined in either the first week $(>1,000$ $\mu \mathrm{mol} / \mathrm{L})$ or the second week postpartum $(\geq 1,400 \mu \mathrm{mol} / \mathrm{L})$ or both of the first 2 wk postpartum relative to cows not SCK in either of the first 2 wk. predicted independent of threshold used. This association was significant at $\geq 1,000 \mu \mathrm{mol} / \mathrm{L}$ of BHBA. The low number of cows above the higher threshold increases the likelihood of a type II error in this analysis. In the second week after calving, the probability of pregnancy decreased with increasing BHBA concentration thresholds, with a 40 to $50 \%$ reduction at thresholds $\geq 1,400 \mu \mathrm{mol} / \mathrm{L}$.

The duration of exposure to elevated circulating BHBA affects the PR/AI. Cows identified as SCK in either of the first 2 wk were $17 \%$ less likely to be pregnant after first AI, whereas cows that remained above the SCK thresholds in both weeks were $53 \%$ less likely to be pregnant. The probability of pregnancy after first insemination in cows classified as SCK in either week was not different $(P=0.28)$ from cows never classified as SCK but was greater than cows classified as SCK in both weeks $(P=0.02$; Table 3$)$. There are few other studies with which to compare these findings. The magnitude of and the rate of recovery from negative energy balance were associated with time to pregnancy (Reist et al., 2003a). Similarly, most of the variation in onset of ovarian activity and time to pregnancy was attributed to the maximum ketone concentration recorded, independent of the week postpartum when it occurred (Reist et al., 2000; Koller et al., 2003).

Time from calving to first insemination is a reflection of management practice regarding the voluntary waiting period and estrus detection efficiency and accuracy. Subclinically ketotic cows in either of the first $2 \mathrm{wk}$ were inseminated $8 \mathrm{~d}$ later than animals that were never SCK. Delayed insemination between cows classified as SCK in either week relative to those classified as SCK in both weeks was not anticipated. This outcome may reflect a differential effect on reproductive efficiency for cows that experience a first elevation in circulating ketone concentrations in the first week (increased risk of uterine disease; Reist et al., 2003a) and second week (increased risk of delayed ovulation; Reist et al., 2000) relative to cows that recover from hyperketonemia before the second week of lactation (Table 3).

There was a significant effect of SCK on time from calving to pregnancy. Concentrations of BHBA that were $\geq 1,000 \mu \mathrm{mol} / \mathrm{L}$ in wk 1 and $\geq 1,400 \mu \mathrm{mol} / \mathrm{L}$ in wk 2 were associated with increased time to pregnancy. This effect was not consistent over time. Animals that were SCK in either week had an adjusted HR of 0.55 at 60 DIM and 0.75 at 120 DIM. Animals SCK in both weeks had an associated HR of 0.52 at $60 \mathrm{DIM}$ and 0.84 at 120 DIM. In other words, the negative effect of SCK early in lactation appears to diminish as cows progress through lactation. Moreover, it is important to note that there was no significant difference in time to pregnancy between cows classified as SCK in either week relative 
to those classified as SCK in both weeks $(P=0.28$; Table 5).

Despite reports on the association between energy balance and commencement of luteal activity, PR/AI, and time to first insemination and to pregnancy, the underlying mechanisms are still not fully clear. The results of the current analysis provide further evidence of residual effects of health problems in the transition period on subsequent reproductive performance. Specifically, SCK in early lactation is associated with impaired reproductive performance 50 to $100 \mathrm{~d}$ later. This delayed effect on reproductive traits has been attributed to increased risk of delayed commencement of ovulation (Butler, 2003). More recently, Leroy et al. (2006) found that in vitro maturation of follicles in media conditions analogous to those follicular fluid concentrations of glucose and BHBA experienced during SCK significantly reduced the ability of fertilized ova to become morula and hatched blastocysts, indicating a direct toxic effect of BHBA and NEFA on maturing ova.

The peak herd level prevalence of SCK has been reported from the second to fifth week postpartum (Andersson and Emanuelson, 1984). Attempts have been made to understand factors that influence when the peak level of SCK occurs within individual herds. One such study by Heuer et al. (2001) reported that season of calving and pen number (specifically management practices such as time away from feed) explained $17 \%$ of the variation in milk acetone concentrations. Thus, application of this data would best identify herds at risk for reproductive failure rather than cows.

Similar to the present study, others reported no association of BCS at calving, or change in BCS early in lactation, with any reproductive parameters (Ruegg and Milton, 1995). The distribution of BCS and BCS loss in this data set was similar between animals that were pregnant to first insemination and those that were not pregnant. Insufficient variation in body condition data has been previously cited as a partial explanation for the inconsistent association between BCS and energy balance (Heuer et al., 2000).

A treatment effect of $\mathrm{Na}$ monensin on time to pregnancy has not been reported. Further, the CRC formulation was not associated with alterations in commencement of luteal activity, days to first insemination, or days to conception, despite consistent reductions in serum BHBA (Abe et al., 1994; Lean et al., 1994; Duffield et al., 1999). No previous study, investigating the effect of monensin, has included ketone information in the same model. Inclusion of BHBA in the same model removes the effect on PR/AI achieved through the improvement of energy status that monensin treatment permits and assigns it to BHBA concentration. Thus, the underlying mechanism to explain this treatment effect is unknown. Monensin ( $22 \mathrm{mg} / \mathrm{kg}$ of $\mathrm{DM}) \mathrm{de}-$ creases days to first ovulation and decreases the number of large follicles before 30 DIM with no change in first service conception risk (Tallam et al., 2003). Both clinical and subclinical endometritis increases time to pregnancy (LeBlanc et al., 2002). This association may represent the link between monensin treatment and a reduced daily probability of pregnancy (HR).

\section{CONCLUSIONS}

Cows diagnosed as SCK in either of the first $2 \mathrm{wk}$ postpartum, using a threshold of serum BHBA concentration $\geq 1,000 \mu \mathrm{mol} / \mathrm{L}$ in the first week postpartum or $\geq 1,400 \mu \mathrm{mol} / \mathrm{L}$ in the second week postpartum, were $20 \%$ less likely to be pregnant at first insemination. The probability of pregnancy was reduced by $50 \%$ in cows experiencing SCK in both of the first 2 wk. Using time to pregnancy as the outcome, SCK in either the first 2 wk postpartum decreased the daily probability of pregnancy (HR) until approximately $165 \mathrm{~d}$ postpartum.

\section{ACKNOWLEDGMENTS}

Financial support was provided by Elanco Animal Health, the University of Guelph Doctor of Veterinary Science program, and Vétoquinol. The technical assistance provided by Eleanor Robinson is greatly appreciated.

\section{REFERENCES}

Abe, N., I. J. Lean, A. Rabiee, J. Porter, and C. Graham. 1994. Effects of sodium monensin on reproductive performance of dairy cattle. II. Effects on metabolites in plasma, resumption of ovarian cyclicity and oestrus in lactating cows. Aust. Vet. J. 71:277-282.

Andersson, L., and U. Emanuelson. 1984. An epidemiological study of hyperketonemia in Swedish dairy cows: Determinants and the relation to fertility. Prev. Vet. Med. 3:449-462.

Bauman, D. E., and W. B. Currie. 1980. Partitioning of nutrients during pregnancy and lactation: A review of mechanisms involving homeostasis and homeorhesis. J. Dairy Sci. 63:1514-1529.

Butler, W. R. 2003. Energy balance relationship with follicular development, ovulation and fertility in postpartum dairy cows. Livest. Prod. Sci. 83:211-218.

Cook, N. B., W. R. Ward, and H. Dobson. 2001. Concentrations of ketones in milk in early lactation, and reproductive performance of dairy cows. Vet. Rec. 148:769-772.

Dawuda, P. M., J. R. Scaife, J. S. Hutchinson, and K. D. Sinclair. 2002. Mechanisms linking under-nutrition and ovarian function in beef heifers. Anim. Reprod. Sci. 74:11-26.

Duffield, T. F., K. E. Leslie, D. Sandals, K. Lissemore, B. W. McBride, J. H. Lumsden, P. Dick, and R. Bagg. 1999. Effect of a monensincontrolled release capsule on cow health and reproductive performance. J. Dairy Sci. 82:2377-2384.

Duffield, T. F., D. Sandals, K. E. Leslie, K. Lissemore, B. W. McBride, J. H. Lumsden, P. Dick, and R. Bagg. 1998. Effect of prepartum administration of monensin in a controlled-release capsule on postpartum energy indicators in lactating dairy cows. J. Dairy Sci. 81:2354-2361.

Ferguson, J. D., D. T. Galligan, and N. Thomsen. 1994. Principal descriptors of body condition score in Holstein cows. J. Dairy Sci. 77:2695-2703. 
Heuer, C., W. M. van Straalen, Y. H. Schukken, A. Dirkzwager, and J. P. T. M. Noordhuizen. 2000. Prediction of energy balance in a high yielding dairy herd in early lactation: Model description and precision. Livest. Prod Sci. 65:91-105.

Heuer, C., A. Wangler, Y. H. Schukken, and J. P. Noordhuizen. 2001. Variability of acetone in milk in a large low-production dairy herd: A longitudinal case study. Vet. J. 161:314-321.

Jolly, P. D., S. McDougall, L. A. Fitzpatrick, K. L. MacMillan, and K. W. Entwistle. 1995. Physiological effects of undernutrition on postpartum anoestrus in cows. J. Reprod. Fertil. Suppl. 49:477-492.

Koller, A., M. Reist, J. W. Blum, and U. Küpfer. 2003. Time empty and ketone body status in the early postpartum period of dairy cows. Reprod. Domest. Anim. 38:41-49.

Lean, I. J., M. Curtis, R. Dyson, and B. Lowe. 1994. Effects of sodium monensin on reproductive performance of dairy cattle. I. Effects on conception rates, calving-to-conception intervals, calving-toheat and milk production in dairy cows. Aust. Vet. J. 71:273-277.

LeBlanc, S. J., T. F. Duffield, K. E. Leslie, K. G. Bateman, G. P. Keefe, J. S. Walton, and W. H. Johnson. 2002. Defining and diagnosing postpartum clinical endometritis and its impact on reproductive performance in dairy cows. J. Dairy Sci. 85:2223-2236.

Leroy, J. L. M. R., T. Vanholder, G. Opsomer, A. Van Soom, and A. de Kruif. 2006. The in vitro development of bovine oocytes after maturation in glucose and $\beta$-hydroxybutyrate concentrations associated with negative energy balance in dairy cows. Reprod. Domest. Anim. 41:119-123.

Plym Forshell, K., L. Andersson, and B. Pehrson. 1991. The relationships between the fertility of dairy cows and clinical and biochemical measurements, with special reference to plasma glucose and milk acetone. Zentralbl. Veterinarmed. A 38:608-616.
Reist, M., D. K. Erdin, D. von Euw, K. M. Tschümperlin, H. Leuenberger, H. M. Hammon, C. Morel, N. Künzi, and J. W. Blum. 2003a. Use of threshold serum and milk ketone concentrations to identify risk for ketosis and endometritis in high-yeilding dairy cows. Am. J. Vet. Res. 64:188-194.

Reist, M., D. K. Erdin, D. von Euw, K. M. Tschümperlin, H. Leuenberger, H. M. Hammon, C. Morel, C. Philipona, Y. Zbinden, N. Kunzi, and J. W. Blum. 2003b. Postpartum reproductive function: Association with energy, metabolic and endocrine status in high yielding dairy cows. Theriogenology 59:1707-1723.

Reist, M., A. Koller, A. Busato, U. Kupfer, and J. W. Blum. 2000. First ovulation and ketone body status in the early postpartum period of dairy cows. Theriogenology 54:685-701.

Ruegg, P. L., and R. L. Milton. 1995. Body condition scores of Holstein cows on Prince Edward Island, Canada: Relationships with yield, reproductive performance, and disease. J. Dairy Sci. 78:552-564.

SAS Institute. 2004. SAS User's Guide: Statistics. 9th ed. SAS Inst. Inc., Cary, NC

Staples, C. R., W. W. Thatcher, and J. H. Clark. 1990. Relationship between ovarian activity and energy status during the early postpartum period of high producing dairy cows. J. Dairy Sci. 73:938-947.

Stata Corporation. 2005. Stata Statistical Software: Release 9.1. Stata Corporation, College Station, TX.

Tallam, S. K., T. F. Duffield, K. E. Leslie, R. Bagg, P. Dick, G. Vessie, and J. S. Walton. 2003. Ovarian follicular activity in lactating Holstein cows supplemented with monensin. J. Dairy Sci. 86:3498-3507.

Villa-Godoy, A., T. L. Hughes, R. S. Emery, L. T. Chapin, and R. L. Fogwell. 1988. Association between energy balance and luteal function in lactating dairy cows. J. Dairy Sci. 71:1063-1072. 